\title{
NEW YORK NEUROLOGICAL SOCIETY.
}

June 5, 1900 .

The President, Dr. Frederick Pelerson, in the chan.

\section{EXOPHTHALNIC GOITRE TREATED BY INTESTINAL} ANTISEPTICS.

1)r. Mary Hutnam Jacobi presented the following case: L. D., aged 22 years, was first seen February 8 th, 1899. She had been well until the age of twenty, when she began to work at a shop for making infants' clothing. She worked from eight until five on button-holes and feather stitching. She began to suffer much from constipation, but was relieved by frequent purgation with licorice powder. At the end of a year menstruation ceased, i. c., in July, 1897 .

Six months later the eyeballs began to be prominent, and at the same time she had flushes of lieat ail over the body, palpitations of the heart, headache, weakness, tremor of hands and feet, especially on rising in the morning, and frequent distress in the stomacli. In the sunnmer of 1898 , constipation was replaced by chronic diarrhea.

In February of this year she had a severe attack of diphtheria, for which she entered Mt. Sinai Hospital. On recovery from this she felt nuwch better for a while.

The thyroid gland was only moderately enlarged and appeared to be slightly larger in the morning at the same time the tremor and diarrhea occurred. Both cardiac sounds were markedly accentuated. No murmurs were heard over the heart, but a systolic murmur was heard over the carotid artery. The pilse was 120 ; respiration was 24 ; sphygnogram was regular and rapid.

The patient complained of constant aching in upper thoracic region between the shoulder blades.

An attempt at a complete milk diet rendered the patient very weak and miserable, and increased the tachycardia to a point where the pulse could not be counted.

The urine was examined by Bonchard's method twice this winter, once in February, and again in March. On the first occasion the toxic coefficient was .579 , on the second, .7 I2.

The patient had been treated by various nervous and vascular tonics, without material benefit, before she came into the hands of Dr. Jacobi. Various disinfectants were used by Dr. Jacobi at different times for a long period, bismuth salicylate and beta naphtol, associated with a daily flushing of the colon with two quarts of water. Under this treatment, and cspecially on account of the color flushings, the diarrhea was 
arrested, and the patient grew steadily stronger. Menstruation returned on April I 5 th, I899, after an amenorrhea of twenty-two months. A third examination of the urine gave an urotoxic coefficient of 1.426 , nearly double the toxicity found in March. For eleven months the pulse remaincel at I2O.

On April 2Ist, the patient was feeling very weak, with much headlache and anorexia, and the urotoxie coefficient was .388 , the only time at which it was subnormal, or any other than excessive. On March $27^{\text {th }}$, after an experiment with thymus gland, the coefficient was 1.662 ; menstruation occurred three days later. After this it was absent until January, I900, when it returned, and has returned regularly ever sinee.

The last urinary examination was made May 22d, Igoo, and the coefficient was then nearly normal, being .432 .

The pulse remained at 120 or over, with scareely an exception for eleven months; then, on January 24 th, it became IoO and dicl not change in spite of an attack of diarrhea and insomnia. On the 7 th of February, rgoo, the medieation was changed to salicylate of soda, of which from 60 to 80 grains were given daily. After ten days the pulse was found to be 93, ten days later 92, and on April 4th, 9o.

An intereurrent attaek of diphtheria treated at lome by muriate of iron, had the effect of lowering the pulse to go.

Dr. E. D. Fisher said that this patient had a very vascular eondition of the thyroid gland. He did not absolutely agree with Dr. Jacobi in the use of intestinal antiseptics. He had found the use of strophanthin for long periods suceessful. That treatinent might be earried out in a case of this kind.

Dr. Wm. H. Porter said he had observed two eases of a similar nature whieh were treated by antisepsis of the alimentary eanal, to prevent toxie infeetion. with better results than had been obtained under other treatment for that class of eases.

Dr. Wm. H. Caswell had found that I5 grains of glyeero-phosphate of soda, given three times a day. had been useful in a ease of this kind. The pulse had fallen from 130 or 140 to 84 or 88 , and remained low for the last two months. All eonstitutional symptoms were very nitueh improved, althongh the exophthalmus had not disappeared, nor was there any decrease in the size of the thyroid. The patient was still doing well.

Dr. Jacobi said that she had paid no systematic attention to this question of the urotoxie coefficient. She had noticed that when the urotoxic coefficicnt was in cxcess of normal. the patient was better. One time it fell below normal, and she was decidedly weakcr with symptoms of more constitutional poisoning, enfirming the idea that poison circulating in the blood and excess of urine toxicity coexisted with the effort of the organism to throw it out. When the toxieity was high, the patient was better; when subnormal, the patient was worse. 